\title{
La amnistía de febrero de 1936 en Cartagena: Verdad y versión. Aproximación a las claves de un proceso de mixtificación política
}

\author{
Pedro Ma ${ }^{a}$ Egea Bruno \\ Universidad de Murcia
}

\begin{abstract}
The amnesty of February, 1936 in Cartagena: Truth and version. Approximation to the keys of a process of a political merging
\end{abstract}

La función de la historia será entonces la de mostrar que las leyes engañan, que los reyes se enmascaran, que el poder ilusiona y que los historiadores mienten.

M. Foucault, Genealogía del racismo

RESUMEN

La violencia fue uno de los usos políticos más reiterados durante los años de la

Segunda República. Su instrumentalización por parte de las opciones más conservadoras les permitió articular toda una estrategia contra el sistema establecido, desde la provocación desestabilizadora a la justificación de la Guerra Civil. La manipulación de la realidad tuvo uno de sus puntos de referencia en la amnistía otorgada en febrero de 1936. En Cartagena la medida revistió una especial trascendencia, al encontrarse detenidos en sus centros penitenciarios personajes de indudable relevancia, desde algunos consejeros de la Generalidad Catalana a Fernando Condés.

PALABRAS CLAVE: Segunda República, Frente Popular, cárcel, motines, violencia política, amnistía, propaganda, extrema derecha, manipulación ideológica, Cartagena.

\section{ABSTRACT}

Violence was one of the most repeated political uses during the years of the Second Republic. Its instrumentalization on the part of the most conservative options allowed them to articulate the whole strategy against the established system, from the destabilizing provocation to the justification of the Civil war. The manipulation of reality had one of its points of reference in the amnesty granted in February, 1936. In Cartagena the measure involved a special transcendency, since in its penitentiary centers prominent figures of undoubted relevancy, from some counselors of the Catalan Generality to Fernando Condés were arrested.

KEY WORDS:

The second Republic, Popular Front, jail, riots, political violence, amnesty, propaganda, extreme right, ideological manipulation, Cartagena. 
La Segunda República española conoció un espectacular incremento de la movilización política, con un importante componente de violencia ${ }^{1}$. La subversión contra el orden establecido, la encarcelación, incluso la ejecución de los adversarios políticos, vertebraron las formas extremas de esa manera de proceder. Su contrapunto fueron las reiteradas demandas de amnistía. Hasta tres se concedieron en los años de 1931-1936. Los usos apuntados y las propuestas de conciliación adquieren significados diversos a la luz de las intenciones que los suscitan. Manipulación política y manipulación histórica se dan la mano en la coyuntura de febrero de 1936. Por la primera - con la formación Frente Popular-se quiso desmovilizar la subversión; por la segunda, se razonó el posicionamiento más reaccionario. La amnistía pactada permitió un punto de equilibrio entre el Gobierno y la oposición, cuya lectura como desarme ideológico puede ser interpretada como un valladar contra la revolución en la línea de G. Munis². En ese contexto naufragó la izquierda burguesa ${ }^{3}$.

La agitación desestabilizadora se aceleró tras la victoria de la coalición de izquierdas en los comicios del día 16. Aquel triunfo alentó el golpismo por parte de la extrema derecha y de ciertos sectores militares, que desde el primer momento quisieron frustrar la toma del poder por parte de sus adversarios, hasta plantearse la intervención del Ejército para anular las elecciones. Frustrado el designio $-\mathrm{y}$ como mejor táctica - desarrollaron todo un formulario de acciones contrarevolucionarias ${ }^{4}$. Su objetivo será doble: deslegitimar el régimen republicano y montar una operación psicológica basada en el desorden y la falta de autoridad: el «gran miedo» que apunta Rafael $\mathrm{Cruz}^{5}$. En último término, les servirá para argumentar el golpe militar de julio de 1936 y la guerra civil. Esa percepción se extenderá fuera de nuestras fronteras y contribuirá a difundir una imagen negativa de la República ${ }^{6}$.

En tal labor medió la deformación de la realidad, creándose en diciembre de 1938 una comisión cuya finalidad era «... instruir las actuaciones encaminadas a demostrar plenamente la ilegitimidad de los poderes actuantes en la República es-

1 ARÓSTEGUI, J.; G. CALLEJA, E. y SOUTO, S., «La violencia política en la España del siglo XX», Cuadernos de Historia Contemporánea, 22 (2000), pp. 53-94. GONZÁLEZ CALLEJA, E., «La dialéctica de las pistolas. La violencia y la fragmentación del poder político durante la Segunda República», en J. Muñoz, J.L. Ledesma y J. Rodrigo (coords.), Culturas y políticas de la violencia en la España del siglo XX Madrid, Editorial Siete Mares, 2005, p. 136.

2 Cfr. MUNIS, G., Jalones de derrota: Promesa de victoria. Crítica y teoría de la revolución española (1930-1939), Madrid, Zero, 1977, p. 252ss.

3 Cfr. AVILÉS, J., La izquierda burguesa y la tragedia de la II República, Madrid, Comunidad Autónoma de Madrid, 2006.

4 Vid. GONZÁLEZ CALLEJA, E., «Aproximación a las subculturas violentas de las derechas antirrepublicanas españolas (1931-1936)», en Pasado y Memoria, 2 (2003), pp. 3-90. Del mismo autor, «La violencia y sus discursos: los límites de la "fascistización" de la derecha española durante el régimen de la Segunda República», en Ayer, 71 (2008), pp. 89-94.

5 CRUZ, R., En el nombre del pueblo. República, rebelión y guerra en la España de 1936, Madrid, Siglo XXI, 2006, p. 5.

6 Cfr. FERNÁNDEZ-LONGORIA, M., «La percepción de los acontecimientos políticos españoles de enero a julio de 1936 en la prensa inglesa», Espacio, Tiempo y Forma. Serie V, Historia Contemporánea, 17 (2005), pp. 191-205. 
pañola en 18 de julio de $1936 \ldots$.... Su única opción pasaba por desactivar la evidencia: «Uno de los resortes que con mayor constancia han sido utilizados por la España marxista en su desaforada propaganda — sucedáneo de una fuerza efectiva que no posee y de un apoyo moral de que está desprovista su causa- es la imputación de facciosa, rebelde y antijurídica con que sin tregua ni reposo moteja a la España Nacional». Se trataba de justificar, a toda costa, la sedición contra el orden establecido: «... que los órganos y las personas que en 18 de julio de 1936 alentaban el Poder adolecían de tales vicios de ilegitimidad en sus títulos y en el ejercicio del mismo que, al alzarse contra ellos el Ejército y el pueblo, no realizaron ningún acto de rebelión contra la Autoridad ni contra la Ley»’7. Esas visiones serán cimentadas desde primera hora por los ideólogos del franquismo y desarrolladas hasta el presente por sus publicistas afines, sin que falten epígonos locales ${ }^{8}$.

A la estrategia de la provocación respondieron las graves alteraciones del orden público suscitadas entre febrero y julio de 1936. En la urbe levantina se iniciaron el 17 de febrero con el motín del Penal y continuaron con la serie de incidentes que pespuntearon aquellos meses, desde los enfrentamientos del 9 de abril —Jueves Santo- a la última actuación de Juan Vicente Fernández, alias el Chipé —un matón al servicio de la derecha—, en la señalada fecha del 19 de julio ${ }^{9}$. La rebelión del presidio - como se verá- fue una de esas situaciones interesadamente adulteradas por los aparatos ideológicos de los vencedores. Lo mismo puede decirse de la amnistía dictada poco después. A esas alturas ya se había puesto en marcha el proceso de mixtificación de la historia, la falsificación del pasado, la transformación de la falacia en verdad oficial.

En otro orden de análisis, los mimbres de la historia de España se entrecruzan de nuevo en Cartagena. El enclave mediterráneo fue, una vez más, protagonista, escenario de acontecimientos de primera magnitud y cita de personajes de indudable trascendencia en el devenir reciente. En esta ocasión recibirá a presos políticos de conocida notoriedad, encarcelados por los sucesos de octubre de 1934, desde los consejeros de la Generalidad de Cataluña a Ramón González Peña, el líder de la revolución asturiana. Uno de ellos -Fernando Condés-, amnistiado en febrero de 1936, acelerará el enfrentamiento nacional con su intervención en la muerte de José Calvo Sotelo, dirigente de Renovación Española, una organización de la extrema derecha.

7 Boletín Oficial del Estado, 22 de diciembre de 1938, pp. 3.079-3.080. VV.AA., Manipulaciones de la Historia, en Temas para el Debate, 147 (2007), pp. 19-53.

8 Vid. REIG TAPIA, A., AntiMoa, Barcelona, Ediciones B, 2006, p. 69ss. FERNÁNDEZ RIQUELME, S., «El verdadero lenguaje de la revolución. Violencia y represión en la Murcia republicana (19341939)», en Arbil, 115 (www.arbil.org.).

9 Cfr. VICTORIA MORENO, D., «Las cofradías de Cartagena durante el siglo XX», en VV.AA., Las cofradías pasionarias de Cartagena, Cartagena, Asamblea Regional de Murcia, 1991, pp. 487-488. PLAZAS ESPINOSA, R., «Tragedia en julio de 1936. La muerte del Chipé», en Cartagena Histórica, 1 (2002), pp. 5-10. RODA ALCANTUD, C., «Memoria y violencia colectiva en el prólogo de la guerra civil española: El linchamiento de El Chipé en Cartagena», en Trujillano Sánchez, J.M. y Gago González, J.M. (eds.), Historia y fuentes orales. Las fuentes orales entre la memoria y la historia. La complementariedad con otras fuentes, Actas VIII ${ }^{a s}$ Jornadas, El Barco de Ávila, 2007, pp. 444-454. 


\section{EL PENAL DE CARTAGENA, DESTINO DE PRESOS POLÍTICOS}

Cartagena es uno de los enclaves militares de mayor envergadura de la Península. Cabecera del Departamento Marítimo del Mediterráneo y sede de una importante base naval que alberga complejas instalaciones militares, desde el Arsenal a cuarteles de Marinería e Infantería de Marina, pasando por el fondeadero de submarinos, los servicios de Ingeniería Naval e Intendencia, la Escuela de Buzos y Submarinistas de la Armada, una relevante estación de radiotelegrafía e importantes depósitos de municiones y combustible. La base es sede operativa de las flotillas de destructores, submarinos y torpederos, junto con diversos barcos de transporte y salvamento. El lugar se singulariza como núcleo industrial dentro de una provincia eminentemente agraria, con referencias obligadas a los sectores minero, naval y químico. Da pie a la formación de una nutrida clase obrera - la mejor organizada a nivel provincial-, en tanto la formación social se desliza hacia planteamientos izquierdistas, con una clara traducción electoral. En 1930 alberga una población de hecho de 102.518 habitantes, sobre un total provincial de 645.449 , lo que la convierte en el segundo núcleo urbano, detrás de la capital ${ }^{10}$.

Cuenta con la correspondiente cárcel de partido, emplazada en el barrio de San Antonio Abad, y con una prisión central —el penal-, que forma parte de la red nacional, junto con los del Dueso, San Miguel de los Reyes (Valencia), Burgos, Santa María del Puerto, Figueras y los reformatorios de Ocaña y Alicante ${ }^{11}$. Se contabilizan dos centros de carácter militar, instalados en el Arsenal —la denominada Grillera- y en el Castillo de San Julián.

El penal será utilizado para ejemplarizar las condenas de los presos políticos. A él vendrá destinado el comité de la huelga de agosto de 1917: Francisco Largo Caballero, Julián Besteiro, Andrés Saborit y Daniel Anguiano. Albergó, luego, a los procesados bajo la égida de Primo de Rivera, empezando por los alcaldes y concejales del régimen derribado. También a Domingo Marsach, por atentar en Barcelona contra el dictador. Los más numerosos se contabilizaron entre los conspiradores antimonárquicos ${ }^{12}$.

La República también encarceló a sus enemigos, de uno y otro signo. Durante el primer bienio — con un gobierno de republicanos de izquierdas y socialistas - la protesta obrera llenó las cárceles de sindicalistas a la sombra de la denominada Ley de Defensa de la República, de 21 de octubre de 1931, promulgada directamente contra la $\mathrm{CNT}^{13}$. En el presidio cartagenero fueron encerrados los sentenciados por los sucesos de Castilblanco (Badajoz), un enfrentamiento ocurrido el 31

10 GONZÁLEZ MARTÍNEZ, C., Guerra Civil en Murcia. Un análisis sobre el poder y los comportamientos colectivos, Murcia, Universidad, 1999, pp. 34-55.

11 Gaceta de Madrid, 21 de noviembre de 1930, pp. 1.030-1.032.

12 Vid. VICTORIA MORENO, D., Cartagena y la actual Región de Murcia durante la dictadura de Primo de Rivera (1923-1930), Murcia, Ediciones Mediterráneo - Ayuntamiento de Cartagena, 2002, p. 333 ss.

13 Vid. Gaceta de Madrid, 22 de octubre de 1931, pp. 420-421. 
de diciembre de 1931 entre campesinos de aquella localidad y la guardia civil, que acabó con el linchamiento de cuatro miembros del cuerpo armado. De los 45 detenidos - de lo que Marañón denominó un nuevo Fuente Ovejuna-, fueron encausados 20 hombres y dos mujeres. Se pronunciaron seis penas de muerte, conmutadas luego por otras de 30 años de reclusión mayor. Recayeron en Pedro Álvarez Bravo, Lucio Bravo Ayuso, Hilario Bermejo Corral, Wenceslao García Galán, Benigno del Prado Romero y Reyes Horcajo Romero ${ }^{14}$.

El propósito golpista de agosto de 1932 —encabezado por el general Sanjurjo- llevó a la cárcel a sus promotores. A extinguir pena llegaron a Cartagena -en enero de 1934- algunos de sus principales implicados: el ex teniente general Cavalcanti, el ex teniente coronel Ugarte y el ex general de división García de la Herranz $^{15}$. De allí pasarían al Castillo de San Julián, donde se les habilitó el alojamiento preciso. Se beneficiaron de la amnistía aprobada el 24 de abril de aquel mismo año, quedando en libertad el día $26^{16}$. Unas semanas más tarde su celda sería ocupada por el general Manuel González Carrasco: «... por haber asistido al banquete que, en honor de los ex ministros de la dictadura Sres. Yanguas Messía y Calvo Sotelo, organizó la minoría monárquica de Renovación Española» ${ }^{17}$. El arresto sólo duró un mes, sin que variase su ideología. En julio de 1936 fue el encargado de iniciar en Valencia la rebelión militar contra la República, aunque no logró forzar la fidelidad de aquella Capitanía.

Durante el segundo bienio republicano, el que se corresponde con la derecha en el poder, la persecución política adquirió su mayor dimensión. El número de presos en la central cartagenera había venido descendiendo hasta entonces de forma continuada. Los 560 registrados el $1^{\circ}$ de enero de 1931 pasaron a 213 en diciembre de aquel año y a 170 en 1932 . El 31 de diciembre de 1933 - con la nueva situación política- ascendieron a 215. Los valores se duplicaron a nivel nacional, saltando — con datos de diciembre- de 6.264 en 1931 a 12.574 en $1933^{18}$.

\section{LOS PRESOS DE OCTUBRE DE 1934}

La represión alcanzó su punto culminante con ocasión del fallido intento revolucionario de octubre de 1934. Las cárceles se llenaron con los partícipes en aquel movimiento, cuando no con sus simpatizantes y aliados circunstanciales, haciéndose proverbial la cifra de 30.000 detenidos. En Cartagena el número de penados superó los 600 , al convertirse en lugar de arribo de algunos de aquellos condenados, empezando por los militares, confinados en el Castillo de San Julián. Los primeros en llegar —el 7 de enero de 1935 - fueron los enjuiciados por los suce-

14 Gaceta de Madrid, 1 de febrero de 1935, p. 959.

15 Cartagena Nueva, 11 de enero de 1934.

16 Cartagena Nueva, 27 de abril de 1934.

17 La Tierra (Cartagena), 7 de junio de 1934.

18 INE, Anuarios de 1931 y 1934. 
sos de Cataluña: el teniente coronel de Infantería Juan Ricart March — jefe de la Guardia de Asalto y Seguridad- y el comandante de Artillería Enrique Pérez Farrás, jefe de los Mozos de Escuadra. A la misma instalación fueron conducidos dos oficiales de la Guardia Civil, el teniente Fernando Condés Romero - que intervino en los conatos de insurrección de Madrid, junto con su amigo el teniente José del Castillo-, y el teniente Gabriel Torrens Llombart, que colaboró con el comité revolucionario de Asturias.

El 28 de abril de 1935 ingresó en la prisión Ramón González Peña, ex diputado socialista y principal dirigente del levantamiento asturiano. Considerado como símbolo de la lucha revolucionaria, representaba para la derecha la figura más representativa del movimiento de octubre, equiparable a las de Largo Caballero y Companys. Su traslado desde Asturias subraya el deseo de acentuar sus sufrimientos: «Ayer tarde llegó a esta en el buque transporte Contramaestre Casado, el cual viene a cumplir en este penal la pena que le fue impuesta por aquel delito, que es la cadena perpetua, al ser indultado de la de muerte". La redacción de la noticia trasluce las precauciones tomadas: «El Casado entró directamente en el Arsenal, y a las 11 de la noche González Peña fue desembarcado. / Le esperaba en el desembarcadero el capitán de la Guardia Civil, señor Pérez Moya, con una escolta de dicho Cuerpo, haciéndose cargo inmediatamente del preso, el cual fue conducido acto seguido al penal, en el auto de la Benemérita». El protocolo fue el de rigor: «En el penal fue recibido por el personal de guardia y el director señor Robles le expuso que desde aquel momento se encontraba sujeto al régimen penitenciario como los demás reclusos. / González Peña contestó, que acataba dicho régimen como un preso más, y que él daría poco trabajo al personal». Se señalaba que había quedado «instalado en celda ordinaria»19. La dureza de ese trato será resaltada en las entrevistas realizadas ${ }^{20}$. La prensa local más conservadora se hizo eco de una interesada interpretación: «... desde anoche, este popular revolucionario ha empezado a saldar con las leyes el delito de su rebeldía contra los Poderes estatuidos» ${ }^{21}$. No se escatimaron anotaciones denigrantes al «cabecilla de la revolución de Asturias» ${ }^{22}$, incluso al «líder de la funestísima y antipatriótica aventura revolucionaria» ${ }^{23}$.

Estuvo incomunicado los primeros cuarenta días: «Durante cuatro horas podía pasear por el patio de pista, donde los presos dan vueltas continuamente, formados en fila» ${ }^{24}$. Esa situación se mantuvo hasta el 8 de junio de 1935. En ese día recibió la visita de destacados miembros de la ejecutiva del PSOE: Luis Jiménez de Asúa — vicepresidente del grupo parlamentario socialista—, Ramón Lamoneda, Si-

19 El Eco de Cartagena, 29 de abril de 1935.

20 Mundo Gráfico (Madrid), 19 de febrero de 1936.

21 El Noticiero (Cartagena), 29 de abril de 1935.

22 El Eco de Cartagena, 29 de abril de 1935.

23 Cartagena Nueva, 30 de abril de 1935.

24 Crónica (Madrid), 1 de marzo de 1936. 
meón Vidarte y Rodolfo Llopis ${ }^{25}$. Dos semanas más tarde se presentarían —con el mismo objeto- Saborit, Martínez Gil, Trifón Gómez, Setién, Alonso Zapata, Marcial y Blázquez, aunque no consiguieron su propósito al encontrarse en trámites de traslado. Este tuvo lugar el 23 de junio, cuando fue destinado a la cárcel de Chinchilla, donde se realizaron las oportunas obras de acondicionamiento para poder alojarlo26. De Chinchilla pasaría - el 27 de julio- al centro penitenciario de Burgos, aunque su mujer permaneció en Cartagena ${ }^{27}$.

La marcha de González Peña se hizo coincidir con la llegada de algunos de los ex consejeros de la Generalidad catalana: Martí Barrera, Pere Mestres, Ventura Gassol y Martí Esteve, que habían sido condenados por el Tribunal de Garantías a 30 años de reclusión por el alzamiento de octubre. Los restantes miembros de aquel Gobierno - con Companys a la cabeza — ingresaron en el Puerto de Santa María. Tampoco en este caso se tasaron las apostillas ignominiosas: «A Ventura le han cortado la melena» ${ }^{28}$.

Aquella estancia supuso un salto cualitativo en las medidas preventivas. Por seguridad, se reforzó la guardia del presidio, pasando el mando a un teniente ${ }^{29}$. El preceptivo aislamiento de 40 días fue su peor experiencia: «... sin leer, sin escribir, sin fumar, sin relacionarse... »30. La desconsideración dispensada a los consejeros fue ocasión de polémica. Se escribió sobre las dificultades con que tropezaban: «... teníamos que comer rancho, con platos y cubiertos de estaño. Y en cuanto a escribir, sólo una carta, a la familia, cada diez días...» ${ }^{31}$. Tales afirmaciones habían sido desmentidas por el director general de Prisiones —Elviro Ordiales Oroz-: «... precisamente los delincuentes comunes se han quejado de la desigualdad en el trato respecto a los ex consejeros de la Generalidad, habiendo sido los elementos más significados de la revolución» 32 . Su paso por el presidio fue de una absoluta discreción. Sólo se conserva una carta de Gassol dirigida el 22 de diciembre de 1935 a Carles Pi i Sunyer —ex alcalde de Barcelona-, recomendando a su colaboradora e incipiente novelista Celia Suñol. Sustenta, con todo, una absoluta confianza en el porvenir más inmediato: «Piensa que se acercan horas de alegría para nosotros y esfuérzate en llevar una que ya sea augurio de las nuestras al hogar de la querida amiga...»33. Por lo demás, aprovechó aquella estancia para escribir una obra de teatro - La dona de níu-, un libro de versos y traducir dos odas de Horacio $^{34}$.

25 El Eco de Cartagena, 8 de junio de 1935 y El Noticiero (Cartagena), 8 de junio de 1935.

26 El Noticiero (Cartagena), 24 de junio de 1935

27 La Tierra (Cartagena), 27 de julio de 1935.

28 Cartagena Nueva, 25 de junio de 1935.

29 Cartagena Nueva, 14 de junio de 1935.

30 Mundo Gráfico (Madrid), 11 de marzo de 1936.

31 Mundo Gráfico (Madrid), 26 de febrero de 1936.

32 El Noticiero (Cartagena), 9 de agosto de 1935.

${ }_{33}$ Biblioteca del Pavelló de la República de la Universitat de Barcelona, Fons Personal Diversos. 1. (9. Ventura Gassol).

34 Mundo Gráfico (Madrid), 26 de febrero de 1936. 
El penal se convirtió en lugar de peregrinación, transformando el hecho de la reclusión en propaganda política. Las iniciativas expresas se dejaron esperar. Una gestión de Fernando Condés en enero de 1936 con Largo Caballero no llegó a prosperar: «Mi respetado y querido amigo: Una comisión de excelentes camaradas cartageneros me han rogado que le escribiera a $\mathrm{V}$. solicitando el favor de que accediera a dar un acto de propaganda marxista en la Plaza de Toros de esta localidad, con la seguridad de que sería un éxito completo [...] el mitin sería una imponente concentración y muy conveniente para estimular a los remisos y elevar el entusiasmo de los conscientes...». Las facilidades eran nulas: «... debe dirigirme la correspondencia a la dirección de mi mujer, que me la pasará de contrabando, para evitar enojosas intervenciones de la censura... $\gg^{35}$. Al mismo interlocutor le dirigió otra misiva Francisco Tello Tortajada, condenado por su implicación en el asesinato del falangista Matías Montero, que no tardó en formar parte del martirologio franquista: «Los compañeros de Cartagena que nos visitan me encargan le diga a usted la satisfacción que les produciría el que viniese por aquí a dirigirles la palabra... ${ }^{36}$. No escatimaron su compromiso conocidos militantes de la Ezquerra, como el ya nombrado Pi i Sunyer, Miguel Santaló —ex ministro-, Pere Corominas - ex consejero de Justicia - Juan Puig y Ferreter — diputado por la Ezquerra y escritor- y Martí Rouret -ex consejero y pedagogo ${ }^{37}$. Como dirían una vez en libertad: "Nos hemos acercado a España, y España nos ha conocido»38.

Los militares recluidos se hicieron notar a finales de enero de 1936 con una huelga de hambre, en un intento de singularizar su causa y participar de algún modo en la campaña electoral abierta: «Hace unos días ingresó en el Castillo de San Julián un subteniente de Aviación condenado a tres años y pérdida de carrera por motivos de aberración moral. / Los presos que cumplen condena en el citado castillo, entre ellos Pérez Farrás y Torrens, con este motivo declararon la huelga del hambre, aun a pesar de que el nuevo preso ocupa celda aislada» ${ }^{39}$. El plante, al que también se sumó Fernando Condés - y que exigía la expulsión inmediata de aquel incómodo compañero-, se prolongó durante cuatro días. La Agrupación Socialista de Cartagena se movilizó, pidiendo la mediación del alcalde (Zenón Martínez Dueso) —que acabó delegando en López-Pinto, gobernador militar de la plaza-y presionando a los propios huelguistas para que cesaran en su actitud $^{40}$. Se puso de relieve la atención deferente que se había dispensado a los condenados monárquicos de agosto de 1932, Cavalcanti entre ellos ${ }^{41}$. Se añadía la provocación política: «El aviador expulsado es un militante de derecha, que se halla afiliado a la Ceda. Dice ser un fervoroso católico, y lleva su misticismo al fana-

35 Archivo Histórico Nacional [AHN]. FC-Causa General, 1565. Exp. 14, N-277.

36 AHN. FC-Causa General, 1565. Exp. 14, N-252.

37 El Noticiero (Cartagena), 14 de septiembre de 1935, 13 de noviembre de 1935 y 2 de enero de 1936.

38 Crónica (Madrid), 1 de marzo de 1936.

39 Cartagena Nueva, 2 de febrero de 1936 y La Voz (Madrid), 31 de enero de 1936.

40 El Noticiero (Cartagena), 1 de febrero de 1936, y Cartagena Nueva, 4 de febrero de 1936.

41 La Libertad (Madrid), 31 de enero de 1936. 
tismo de pasarse todas las tardes dos horas de rodillas, con un rosario en la mano, rezando o simulando que reza. / Al llegar al castillo solicitó autorización, que le fue concedida, para colgar en su celda un crucifijo de marfil, un cuadro de la Virgen del Carmen y un retrato de Gil Robles, en el que éste aparece en actitud tribunicia»42.

Más allá de las personalidades, los arrestados por motivos políticos fueron muy numerosos: «La población penal se compone de 600 reclusos, de los cuales 400 son socialistas y sindicalistas» ${ }^{43}$. Su presencia será aprovechada para concitar voluntades contra el Gobierno. El posicionamiento del Partido Comunista fue el más temprano. Ya en julio de 1935 aparecieron las primeras señales de agitación y propaganda: «... un pasquín dirigido a los antifascistas, en el sentido de pedir una amnistía de todos los presos políticos "44. En las redadas policiales dirigidas contra sus reuniones clandestinas - realizadas a veces en mitad de la calle- se aprehendían, junto a folletos y prensa de la organización, escritos de esa significación - Desde la cárcel, La pericia policíaca y La justicia burguesa- y recibos de donativos extendidos a las víctimas de Asturias. Su movilización fue continua, como denotan los arrestos de noviembre de 1935: «Han sido detenidos dos afiliados al Partido Comunista, por intentar hacer propaganda subversiva entre las tropas de la guarnición. / Ayer mañana intentaron hacer esta propaganda con la guardia del penal. Uno de ellos es el comunista Blasco ${ }^{45}$, que el sábado salió en libertad de la cárcel de San Antón, y el otro es uno perteneciente a la Juventud Comunista, que se encuentra en esta haciendo propaganda» ${ }^{46}$.

Una acción más decidida —aunque sin la discreción necesaria — tuvo lugar en diciembre de 1935: «Hace ya días tuvimos noticias de que se tramaban ciertos manejos revolucionarios, pero de ellos no quisimos decir nada por prudencia, ya que sabíamos que las autoridades estaban al tanto y no era caso de estropear sus planes». Se trataba de asaltar el recinto carcelario: «Elementos extremistas de la calle estaban en combinación con los de dentro con el objeto de aprovechar el momento de relevo de los guardianes de prisiones y cayendo sobre ellos por sorpresa apoderarse de las pistolas que llevan como armamento y con ellas abrirse paso hasta la calle en unión de los demás reclusos». La delación abortó el plan: «El proyecto estaba bien organizado y ha fracasado por confidencias secretas que llegaron hasta el director señor Robles, el cual ha adoptado las medidas propias del caso, recluyendo en celdas a varios de los más destacados elementos ${ }^{47}$.

La amnistía se convirtió -inevitablemente- en el eje central de la campaña electoral que articuló la coalición de izquierdas para disputar los comicios convo-

42 El Heraldo de Madrid, 7 de febrero de 1936.

43 El Eco de Cartagena, 27 de diciembre de 1935.

44 Cartagena Nueva, 3 de julio de 1935.

${ }^{45}$ Se trata de Ramón Blasco Blanco, secretario general del comité comarcal del PCE.

46 El Noticiero (Cartagena), 25 de noviembre de 1935.

47 El Eco de Cartagena, 27 de diciembre de 1935. 
cados para el 16 de febrero de 1936. Esa fue la tónica general, que en Cartagena alcanzó su mejor expresión en el mitin más importante, el celebrado en la noche del 14 de febrero en el cine Sport $t^{48}$. Ahora bien, en esa demanda, los intereses de la izquierda burguesa no pasaban de ser meramente circunstanciales.

\section{EL MOTÍN DE FEBRERO DE 1936}

Las elecciones dieron el triunfo - también en Cartagena - al Frente Popular. Al día siguiente la ciudad vive en plena marejada política, la que acompaña a un escrutinio especialmente tenso, dada la fractura social que ha acentuado el debate electora ${ }^{49}$. En ese ambiente, alrededor de las diez y media de la mañana, estalla un motín en la prisión central. «Los penados [...] se abalanzaron sobre un grupo de guardias del servicio de la prisión, con los que iba el oficial don Teófilo Arias, y les arrebataron las pistolas, disparando un recluso llamado Bou Nadal sobre el vigilante don José Antonio García García, que recibió un balazo en la parte superior del vientre; los otros funcionarios fueron encerrados en las celdas». En la revuelta alienta el oscuro resentimiento de los presos comunes contra los internos de contrastado impacto mediático: «... los reclusos de este penal intentaron pasar a la nave donde están instalados los presos políticos de la Generalidad...». Lo relata en primera persona Ventura Gassol: «Fue una situación verdaderamente comprometida, que pudo convertirse en una tragedia. Los penados querían, amparándose en nosotros, como diputados, salir a la calle. Yo les hablé y hablé al director. Surgieron armas por todas partes. Fue un instante de gran peligro...». Un instinto primario alentó el motín: «... se explica esa exaltación, ese ciego propósito. Una condena política — cadena perpetua, por ejemplo— puede acortar sus plazos. Pero una condena por delito común - y sobre todo ahora, sin indultos - se ha de cumplir día a día, año a año ¿Se piensa en lo que es para un hombre decir: He de pasarme aquí, entre estos muros, diez y ocho años? Esta consideración ha de llevar, necesariamente, a los más ciegos propósitos. Salir se convierte para esos hombres en una obsesión» ${ }^{50}$.

La insubordinación no tardó en exteriorizarse: «Un grupo de penados pegó fuego a las colchonetas y bien pronto se inició el fuego, aunque no muy intenso, si bien el humo era tan denso que envolvía toda la prisión „51. La acción fue pronto desarbolada por la intervención de las fuerzas de orden público y personal de servicio del penal ${ }^{52}$. Al lugar de los hechos acudió la plana mayor del poder local. La

48 El Noticiero (Cartagena), 15 de febrero de 1936.

49 Para su desarrollo local es obligada la referencia de MARTínEZ LEAL, J., República y Guerra Civil en Cartagena (1931-1939), Murcia, Ayuntamiento de Cartagena - Universidad de Murcia, 1993, pp. 141-154. De corte más coyuntural, FRANCO FERNÁNDEZ, F.J., «Las elecciones de febrero de 1936 en Cartagena», en Cartagena Histórica, 2 (2003), pp. 45-51.

50 Mundo Gráfico (Madrid), 26 de febrero de 1936.

51 La Tierra (Cartagena), 18 de febrero de 1936.

52 El Noticiero (Cartagena), 17 de febrero de 1936. 
defensa del orden establecido se convirtió en gesto de propaganda. Hicieron acto de presencia el jefe de la Base Naval —vicealmirante Juan Cervera- y el gobernador militar, López-Pinto, conocidos por su claro posicionamiento antirrepublicano. Con ellos el alcalde, el juez de Instrucción y el secretario judicial. El exterior del edificio quedó custodiado por las fuerzas de Marinería y Ejército.

No fue una actuación aislada. En los mismos días hubo tumultos similares casi calcados en cuanto a objetivos y desarrollo- en los penales de San Miguel de los Reyes (Valencia), Burgos, Chinchilla y Santoña. Se insistía, no obstante, en su organización espontánea: «Los penados, seguramente por una exaltación debida a las noticias del triunfo electoral de izquierda, se hallaban algo alterados y sin saber cómo se iniciara el movimiento "53. En todos los casos, según Azaña, afloraba el contexto político: «En los penales hay motines. Los promueven los presos por delitos comunes, que se alborotan porque los presos políticos van a salir y ellos no. Con este motivo han ocurrido cosas graves los días pasados en Burgos y Cartagena. En Burgos, los presos comunes han estado a punto de asesinar a González Peña, y, en Cartagena, los consejeros de la Generalidad han corrido serio peligro...» ${ }^{54}$.

El plante de los comunes, en situaciones de efervescencia política, tenía precedentes. En Cartagena ya había pasado con ocasión de la amnistía de abril de 1931, aunque entonces no fue a más ${ }^{55}$. En 1936 las agencias de prensa vincularon los acontecimientos a la inmediatez política: «Al enterarse los reclusos de que habían noticias de un probable triunfo de izquierdas se amotinaron pidiendo la libertad... ${ }^{56}$. De ello se hicieron eco los portavoces de las opciones pequeño burguesas. Los editoriales locales apuntaban en la misma dirección, haciendo referencia «... a la impaciencia, quizá mal aconsejada, de los reclusos...». Terciaban reflexiones de mayor calado, justamente en los posicionamientos ultraconservadores: "Con motivo del incidente anteriormente relatado ayer tarde circuló el rumor de que el incendio había sido provocado por las derechas» ${ }^{57}$. Desde el centro se convenía en quitar hierro al asunto: «Por lo demás afortunadamente nada: ruido, aparato represor, obligado por cierto, humo, inquietud ciudadana..., los revoltosos vueltos a la realidad y el ambiente de la ciudad, de nuevo vuelto a la temperatura normal, a excepción del termómetro político en el que subía y bajaba la columna marcadora, según las noticias que se iban recibiendo y se reciben de los escrutinios parciales» 58 .

Lo ocurrido trató de ser explotado por las expectativas políticas en juego. La derecha — siguiendo su estrategia, ya bien perfilada—, estuvo interesada en magnificar el motín. La izquierda moderada, trató de restarle importancia: «Del suceso

53 La Tierra (Cartagena), 18 de febrero de 1936.

${ }^{54}$ AZAÑA, M., Memorias de guerra, 1936-1939, Barcelona, Grijalbo Mondadori, 1978, p. 18.

55 La Tierra (Cartagena), 18 de abril de 1931.

56 EL Noticiero (Cartagena), 17 de febrero de 1936.

57 Cartagena Nueva, 18 de febrero de 1936.

58 El Noticiero (Cartagena), 18 de febrero de 1936. 
de ayer en el penal, sólo queda el mal recuerdo, un hombre herido y el proceso judicial. / El recuerdo pronto se borrará y ojala no surjan recordatorios; del herido, con satisfacción anunciamos que, afortunadamente, la herida no tiene la gravedad que en un principio se creyó y que el señor García se encuentra mejorado; y del proceso judicial, sólo podemos decir que sigue su lógico curso. / Y para terminar, debemos advertir que en el suceso no hubo que lamentar otras desgracias, como parece ser que se ha propalado por ahí, con el afán, sin duda, de abultar los hechos» $" 59$.

Las fuentes comunistas lo integraron en su acervo imaginario: «El 17 de febrero de 1936 encabezamos una manifestación que puso en libertad a los presos políticos del penal de Cartagena» ${ }^{60}$. No existió tal acción. De haberse producido se hubieran multiplicado sus ecos. Sólo el afán de protagonismo o las leyes de la memoria - se escribe en 1952-, pueden explicar la tergiversación de aquella realidad concreta. Es cierto que la actuación del PCE fue contundente en otros momentos: «En los siguientes días [al 17 de febrero] nos incautamos de un amplio local propiedad de un reaccionario ${ }^{61}[\ldots]$ Posteriormente organizamos tres grandes manifestaciones en las que a estacazos poníamos en fuga, arrojándolos de sus propios antros, a los fascistas militares y civiles. Nos hacíamos dueños de la calle algunas horas. Con una de estas manifestaciones evitamos por primera vez en la historia de Cartagena la salida de las procesiones de Semana Santa. En nuestras manifestaciones se arrastraban a cenetistas y socialistas " ${ }^{62}$. La intervención más violenta, datada en la madrugada del 20 de febrero, fue el intento de incendio del Centro de Acción Popular, emplazado en la calle Mayor ${ }^{63}$.

Aquellos días hubo manifestaciones de izquierdas, pero ninguna se dirigió al penal. No hay duda de que tras el triunfo electoral se ocupó la calle ${ }^{64}$, aunque las convocatorias no pasaron de ser explosiones espontáneas de júbilo, sin consecuencias desestabilizadoras y fácilmente controlables, como la que se formó el 18 de febrero: «Los guardias de Seguridad Beltrán Peñas y Ponce, han presentando a Carmen Fernández Cayuela, de 31 años, con domicilio en Orcel, 23 bajo, la que fue detenida en la calle del Cañón llevando en la mano una bandera con los colores nacionales [republicanos], capitaneando una manifestación o grupo de unas noventa personas entre mujeres y niños, dando vivas a la República, promoviendo

59 El Noticiero (Cartagena), 18 de febrero de 1936.

60 Archivo Histórico del Partido Comunista de España [AHPCE]. Manuscritos, Tesis y Memorias. Carpeta 38, B. García, Algunos datos característicos sobre Cartagena, (4 de marzo de 1952).

61 Se trata de José Maestre Pérez, viejo político conservador, ex ministro de la Monarquía y brazo derecho en Cartagena de Juan de la Cierva. Fallecido en 1933, sus herederos disfrutaban de un magnífico inmueble en la Plaza de San Francisco, luego rotulada de La Pasionaria. Vid. EGEA BRUNO, P.M., La política y los políticos en la Cartagena de Alfonso XIII, Cartagena, Ayuntamiento de Cartagena - Caja de Ahorros del Mediterráneo, 1990.

62 AHPCE. Manuscritos, Tesis y Memorias. Carp. 38...

${ }_{63}$ Cartagena Nueva, 20 de febrero de 1936.

64 Vid. MARCO, J., "La multitud invadió las calles. Experiencia, repertorios y marcos simbólicos de la protesta (1931-1936)", en Ayeres en discusión. Temas clave de Historia Contemporánea hoy. IX Congreso de la Asociación de Historia Contemporánea, Murcia, 17, 18 y 19 de septiembre de 2008. 
con tal motivo un escándalo» 65 . Lo mismo puede decirse de la del 19 de febrero: «Tan pronto como se conoció la noticia de que Azaña había sido encargado de formar Gobierno empezaron a formarse manifestaciones que recorrieron las calles, dando vivas a la República y cantando la Internacional. / Las manifestaciones duraron hasta altas horas de la noche, sin que ocurriera el menor incidente»66.

\section{LA LIBERTAD DE LOS PRESOS: UN CLAMOR POPULAR}

El 20 de febrero se restauraron los Ayuntamientos elegidos el 12 de abril de 1931, destituidos a raíz de los sucesos de octubre de 1934. En Cartagena, la reposición fue acompañada de una imponente marcha popular —más de 15.000 ciudadanos-, la mayor conocida hasta ese momento. Como en otros puntos, se revistió de carácter lúdico - música y banderas - y fue todo un símbolo del poder y la identidad de la izquierda. Ocupación del espacio público, connotación de liberación laboral, concurso de organizaciones juveniles como ostentación de fuerza y concreción escenificada de las víctimas: «Abrían marcha las Juventudes Republicanas, Socialista y Comunista, a las que seguían las esposas de los presos políticos que se encuentran en ésta, señores Martín Esteve, Conde y Garrido. / Después una fila de concejales republicanos y socialistas, con la directiva de los respectivos comités, con banderas y bandas de música [...] Durante el trayecto fueron constantemente vitoreados y aplaudidos, habiendo cerrado el Comercio para que su dependencia pudiera asistir al acto»67.

El grito más repetido fue el de amnistía, en cuya reivindicación sobresalía el protagonismo de las mujeres: «Pasado el día 16 [de febrero], en el cual ellas dieron la más alta prueba de entusiasmo por la consecución de la victoria obtenida para el Frente Popular de Izquierdas, las hemos visto disfrutar de la libertad conseguida en las urnas con más entusiasmo que los hombres en la magna manifestación celebrada ayer. / Con su fina sensibilidad, pronto han sabido comprender lo que esta victoria significa para los familiares de los miles de obreros presos y expatriados, como también para aquellas que perdieron a sus hijos y a sus esposos, las cuales ven aproximarse hoy la hora de la verdadera justicia. / Por eso, véaselas demandar ¡Amnistía!, enrojecidas de entusiasmo. Era el grito de las madres e hijas que en toda España la están esperando ansiadamente» ${ }^{68}$.

Los manifestantes se congregaron frente al Ayuntamiento, en cuyo balcón principal se encontraban los ediles repuestos. Una voz anónima se dirigió al alcalde, expresando sin tapujos el deseo de los congregados: «En nombre de este pueblo que os acompaña esta tarde he de haceros una advertencia. Este pueblo

\footnotetext{
65 Cartagena Nueva, 18 de febrero de 1936.

66 El Noticiero (Cartagena), 20 de febrero de 1936 y La Libertad (Madrid), 21 de febrero de 1936.

67 El Noticiero (Cartagena), 20 de febrero de 1936.

68 El Noticiero (Cartagena), 21 de febrero de 1936.
} 
que el domingo pasado [16 de febrero] os restituyó en las urnas pacíficamente, tiene un anhelo de honradez y de justicia que desde hace mucho tiempo necesita, y os advierte que si por segunda vez sufre un desengaño hará caer sobre vosotros el peso... (los fuertes rumores impiden oír las últimas palabras) / Tenéis que administrar justicia por que así lo piden los cinco mil muertos de Asturias y no hay que olvidar hoy que el pueblo muestra su alegría, que hay cinco mil madres que lloran a los suyos. (Ovación). / En nombre del pueblo os pido que la primera obra del Gobierno de esta República reconquistada por el pueblo trabajador sea la liberación de los treinta mil presos. (Muy bien, muy bien. Grandes aplausos)» 69 .

La intervención del repuesto alcalde - César Serrano, de Unión Republicanaes trasunto de la dualidad que vertebraba a la coalición de izquierdas: "Yo quiero que os manifestéis con la mayor cordura, con la mayor sensatez, que no deis motivo a que digan que nosotros somos los hombres del desorden; es preciso demostrar que más revolucionarios son ellos que no nosotros. Por lo tanto yo pido al pueblo que se conduzca con la mayor cordura y sensatez y que os disolváis sin que se promueva el más pequeño motín... »70. A esa moderación se oponían las propuestas más radicales, surgidas en el seno de la misma alianza. En la sesión municipal, celebrada a continuación, una comisión del Frente Popular presentó al cabildo - para que fueran trasmitidas al Gobierno de la República con la mayor urgencia - las conclusiones que expresaban el sentir de los manifestantes: «Primero. Felicitar llenos de emoción a dicho Gobierno por su exaltación al poder, que supone el rescate de la República. / Segundo. Haber visto con gran satisfacción la reposición de nuestro legítimo Ayuntamiento. Tercero. Que por el Gobierno se busque una fórmula por la que puedan ser inmediatamente libertados los presos políticos y sociales, y / Cuarto. Que inmediatamente sean separados de sus cargos por considerarlos enemigos del régimen los señores Primer Jefe de la Base Naval de Cartagena [contralmirante Juan Cervera Valderrama]; el Gobernador Militar de la Plaza don José López Pinto; el Juez de Instrucción de Cartagena don José González, y el Juez Municipal don José Dodero " ${ }^{71}$. Algunos concejales plantearon la remoción de los funcionarios municipales refractarios al régimen republicano, empezando por secretario del Ayuntamiento, Julio García Vaso.

En el sentir de Azaña, que formó Gobierno el 19 de febrero, la consecuencia de los motines fue acelerar la concesión de la amnistía: «... Esta noche se han sublevado los penados de Chinchilla, San Miguel de los Reyes, Santoña y algún otro penal más. Es urgente conceder la amnistía, aunque en el pacto electoral se conviene en someterlo a las nuevas Cortes ${ }^{72}$. Dada la necesaria premura, se hizo uso de los mecanismos previstos en la Constitución de 1931, sin salirse en lo más mínimo de la legalidad vigente, en contra de lo sostenido por la propaganda más re-

69 Ibidem.

70 El Noticiero (Cartagena), 21 de febrero de 1936.

71 Archivo Municipal de Cartagena. Caja 1.668. Exp. 22. Informe del Frente Popular de Izquierdas sobre la manifestación del pueblo de Cartagena del 12 de abril de 1936 [sic].

72 AZAÑA, M., op. cit., p. 18. 
accionaria: «Nos ha parecido imposible que la gente se aguante más de un mes, hasta que las nuevas Cortes puedan votarla. Saldremos a motín por día. Después de dar vueltas al asunto, quedamos en presentar a la Diputación Permanente de las Cortes actuales un proyecto de decreto de Amnistía. En la Diputación no tenemos más que cinco votos, de 21. Pero cabe esperar que, bajo la presión de las circunstancias, las derechas voten la propuesta del Gobierno. Martínez Barrio se ha encargado de hacer las exploraciones convenientes, empezando por Maura» ${ }^{73}$.

La otra opción —la del decreto— nunca se contempló: «[Maura] también está conforme con que se dé la amnistía ahora, y si tropezamos con alguna dificultad en la Diputación Permanente, que la dicte por decreto. Le contesté que de ningún modo lo haría. Si creen que la amnistía es necesaria y urgente, que la voten en la Diputación. El decreto sería ilegal y me lo echarían en cara. Lo que yo quiero, naturalmente, es que den sus votos para ello, y tienen tanto miedo que, si no llevase el proyecto de ley a la Diputación de las Cortes, acabarían por venir a pedírmelo " 74 El artículo 80 de la Constitución era tajante al respecto: «Cuando no se halle reunido el Congreso, el Presidente, a propuesta y por acuerdo unánime del Gobierno y con la aprobación de los dos tercios de la Diputación Permanente, podrá estatuir por decreto sobre materias reservadas a la competencia de las Cortes, en los casos excepcionales que requieran urgente decisión, o cuando lo demande la defensa de la República». En ese extremo se encontraban —art. 102- los acuerdos sobre las amnistías.

El 21 de febrero un Decreto-ley atendía la exigencia popular: «Siendo inequívoca la significación del resultado de las elecciones a Diputados a Cortes en cuanto a la concesión de una amnistía por delitos políticos y sociales, a favor de la cual se ha pronunciado la mayoría del Cuerpo electoral, y tratándose de una medida de pacificación conveniente al bien público y a la tranquilidad de la vida nacional, en que están interesados por igual todos los sectores políticos... $\gg^{75}$. Una Orden circular establecía al día siguiente el procedimiento para aplicar el precepto a la jurisdicción militar. Se ponía especial acento en su pronto cumplimiento: «La aplicación de la amnistía tendrá carácter urgente y las Audiencias encargadas de su aplicación adoptarán las medidas necesarias para que inmediatamente sean puestos en libertad a aquellos a quienes alcancen sus beneficios, sin perjuicio de que después se formalice la concesión en los correspondientes procedimientos »76.

A la más estricta legalidad, se añadió el consenso de todas las formaciones políticas, con una Diputación Permanente nombrada por las Cortes anteriores, cuya composición se correspondía con la ya desaparecida mayoría de centro-derecha. El criterio de clase se convertía en trampantojo de la realidad política.

\footnotetext{
73 AZAÑA, M. Memorias de guerra, 1936-1939, Barcelona, Grijalbo Mondadori, 1996, pp. $20-21$.

74 Ibidem, p. 21.

75 Gaceta de Madrid, 22 de febrero de 1936, p. 1.515.

76 Gaceta de Madrid, 23 de febrero de 1936, p. 1.548.
} 
Azaña era consciente del papel que estaba asumiendo, aunque tal vez desconociese la estrategia de sus adversarios políticos, que usaban al Frente Popular como parapeto de la contrarrevolución.

\section{UNA EXCARCELACIÓN MATIZADA}

El mismo día 21, a las pocas horas de promulgarse la disposición anotada, fueron puestos en libertad los consejeros de la Generalidad ${ }^{77}$. En la siguiente jornada fue excarcelado Pérez Farrás, acompañándole por la ciudad una manifestación ${ }^{78}$. En ningún momento se produjo una salida masiva de presos: «En virtud del decreto de amnistía hasta la fecha - 27 de febrero- han sido puestos en libertad en esta prisión, aparte de los consejeros de la Generalidad, que lo fueron anteriormente, 96 individuos que estaban presos por los sucesos de Castilblanco, Jaén, Málaga y otras localidades, quedando todavía otros por libertar, pendientes de la tramitación de sus respectivos expedientes de amnistía ${ }^{79}$. Uno de esos casos fue el Francisco Tello, trasladado a la cárcel de Madrid el 9 de marzo de $1936^{80}$. Una semana más tarde se hizo pública la petición de 31 presos que seguían recluidos y que estaban «... condenados por delitos idénticos a los que cometieron gran número de camaradas que han sido puestos en libertad [...] Juntos, alegan, han luchado contra quienes querían deshonrar el régimen que el pueblo se ha dado libremente.... ${ }^{81}$.

La demanda se mantuvo viva. El 28 de febrero el alcalde se sentió obligado a telegrafiar al ministro de Justicia, «... interesándose para que sean puestos en libertad lo antes posible los presos políticos y sociales que se encuentran en el Castillo de San Julián y en este penal»82. Ante la presión popular, el ministro de Justicia -Antonio Lara Zárate - se vio precisado a facilitar la ejecución de lo dictado y establecer «... un procedimiento breve y sencillo para la resolución de aquellos casos en que indebidamente deje de aplicarse...». Al parecer se estaba tropezando con el obstruccionismo de las Audiencias provinciales, de ahí la propuesta de apertura como vía ejecutoria del Tribunal Supremo ${ }^{83}$. Otro tanto se dispuso — por idénticos motivos- para las jurisdicciones de Guerra y Marina ${ }^{84}$.

La amnistía no fue completa. A mediados de marzo las organizaciones obreras de Cartagena seguían requiriendo la libertad de los presos políticos, la revisión de las causas por delitos sociales, la suspensión de los traslados y la reducción de las

77 Mundo Gráfico (Madrid), 4 de marzo de 1936.

78 El Noticiero (Cartagena), 22 de febrero de 1936.

79 El Noticiero (Cartagena), 27 de febrero de 1936.

80 El Heraldo de Madrid, 10 de marzo de 1936.

81 Ibidem.

82 El Noticiero (Cartagena), 28 de febrero de 1936.

83 Gaceta de Madrid, 29 de febrero de 1936, p. 1.691.

84 Gaceta de Madrid, 4 de marzo de 1936, p. 1.819. 
penas a los comunes ${ }^{85}$. Añadían la destitución de los jueces de Instrucción y Municipa| ${ }^{86}$. El 5 de abril, en un mitin de la Alianza Obrera y Campesina celebrado en la Plaza de Toros, José Díaz — secretario general del Partido Comunista de España-, resaltó las carencias de la ley: «... todavía en esta cuestión hay muchos camaradas; muchos obreros anarquistas, comunistas, socialistas y sin partido que, por haber considerado el Gobierno anterior reaccionario los hechos a su manera, han sido condenados como incursos en delitos comunes y hay un trámite demasiado lento para que estos compañeros gocen de la libertad, como la gozan las que ya la tienen, y es necesario que el Gobierno se dé cuenta que nosotros queremos, que nosotros pedimos y que nosotros exigimos, que todos los presos condenados o no condenados que son de nuestra clase y que nosotros sabemos que lo están por delitos de tipo social y político, que están en la cárcel por haber luchado contra el fascio, que no se tarde ni una semana más en que todos ellos gocen de la libertad, lo mismo que los otros que ya están en la calle» ${ }^{87}$.

Lo repetía -el 1 de mayo de 1936-Pedro García Lorente, dirigente local de los sindicatos de oposición de la CNT, «De no producirse el indulto sería tanto como no hacer cumplir aquella propaganda que todos hicimos por los treinta mil presos, pues quedan todavía bastantes de aquel bienio negro, que habiendo cometido delitos sociales se les imputan delitos comunes y siguen sufriendo en cárceles y presidios la tiranía del bienio negro...». González Peña, presente en el acto, recogió el guante: «... podéis tener la seguridad, camaradas de Cartagena, que no sabríamos cumplir con nuestro deber si permitiésemos con nuestra actitud o con nuestro olvido, que quedasen en la cárcel o en los presidios ni uno solo de aquellos camaradas, que cometiendo un delito social los Tribunales llamados de Justicia de nuestro país les han calificado de diferente modo. Y que esto no es una vana promesa, sino que será pronto una realidad, está en el hecho de que uno de los primeros acuerdos tomados por los grupos obreros que integramos el Frente Popular, ha sido el de pedir al Gobierno una ampliación de la Ley de amnistía como asimismo un complemento de indulto que abarque aquellos delitos comunes que estuviesen en condiciones de percibirlo, y esto va a ser muy pronto una realidad» 88 .

El 28 de abril se había promulgado el proyecto de ley que ratificaba la prescripción del 21 de febrero, cumpliendo así los requisitos que señalaba el artículo 80 de la Constitución. En la providencia se incluían ahora los delitos comprendidos en el Código de Justicia Militar y los sociales que habían sido considerados como comunes, «... ejecutados por rebeldes o sediciosos durante la rebelión o sedición y para sus fines» ${ }^{89}$. Todavía quedaron presos en las cárceles.

\footnotetext{
85 La Tierra (Cartagena), 14 de marzo de 1936.

86 El Noticiero (Cartagena), 14 de marzo de 1936.

87 El Noticiero (Cartagena), 6 de abril de 1936.

88 El Noticiero (Cartagena), 2 de mayo de 1936.

89 Gaceta de Madrid, 29 de abril de 1936, pp. 870-871.
} 


\section{LOS EXPEDIENTES DE CONDÉS Y TORRENS: SU PROYECCIÓN SOBRE CARTAGENA}

Los casos más problemáticos fueron los de los guardias civiles. El $1^{\circ}$ de julio de 1936 se aprobó la vuelta a aquel Instituto del teniente Fernando Condés Romero, aunque en situación de disponible forzoso; agregado para haberes, documentación y demás efectos al 14ํ. Tercio, con sede en Madrid ${ }^{90}$. Ascendido a capitán, será quien dirija al grupo de guardias de Asalto y militantes socialistas que detengan y den muerte a Calvo Sotelo, aunque el autor material fue Luis Cuenca, de la organización juvenil. Encontraría su hora — tal vez de forma deliberada ${ }^{91}$ — el 23 de julio de 1936, luchando en el Alto del León (Sierra de Guadarrama). Su nombre quedó vinculado a Cartagena, donde debió trabar sólidas relaciones políticas y personales, como refleja la nota necrológica publicada en la prensa local: «Fernando Condés era como cosa nuestra; su estancia en San Julián nos había hecho conocer su voluntad y decisión por la causa de la libertad, su bondad y sensibilidad extremada, y nuestro aprecio y estima por él será siempre recordado con dolor»92. Las milicias cartageneras recibieron la denominación de Batallón Fernando Condés. También las conocidas como Casas Baratas se rotularon con su nombre.

En el expediente de Gabriel Torrens pesaron aún más las presiones de la Dirección General de la Guardia Civil. El 27 de marzo Pérez Farrás llegó de nuevo a Cartagena para recabar apoyos que acabasen con su encierro ${ }^{93}$. A la campaña se sumaron las fuerzas de izquierda de Ujo, la localidad asturiana donde estuvo destinado en octubre de $1934^{94}$. El 20 de abril, el alcalde se dirigió por telegrama a Manuel Azaña: «Ayuntamiento mi presidencia sesión celebrada ayer interpretando sentir unánime fuerzas políticas integran Frente Popular acordó interesar V.E. valiosa intervención cerca autoridad competente a fin que rápidamente sea otorgada libertad por consecuencia amnistía últimamente concedida a Teniente Guardia Civil Gabriel Torrens condenado delito rebelión militar octubre 1934 Oviedo y preso Castillo San Julián esta ciudad. Lo que cumplimentando acuerdo trasládalo confiado sentimientos humanidad son proverbiales V.E. serán eficientísimo acicate para logro aspiraciones ansias populares inspiradas en deseo reintegrar su hogar a quien por causa política vese privado libertad que hace ya tiempo gozan otros compañeros iguales circunstancias» ${ }^{95}$.

90 Gaceta de Madrid, 2 de julio de 1936, p. 50.

91 Fernando Condés se entrevistó con Prieto a los pocos días del atentado, manifestándole su deseo de suicidarse. La respuesta del político bilbaíno fue contundente: «Suicidarse sería una estupidez. Van a sobrarle ocasiones de sacrificar heroicamente su vida en la lucha que, de modo ineludible, comenzará pronto, dentro de días o dentro de horas». Cfr. PRIETO, I., Convulsiones de España, México, Oasis, 1969, I, p. 162.

92 El Noticiero (Cartagena), 31 de julio de 1936.

93 El Noticiero (Cartagena), 27 de marzo de 1936.

94 El Heraldo de Madrid, 31 de marzo de 1936.

95 El Noticiero (Cartagena), 20 de abril de 1936. 
La libertad provisional le llegaría una vez iniciada la Guerra Civil, el 27 de julio de 1936. La población no había olvidado su causa: «Al llegar al Ayuntamiento fue ovacionado por el público que estaba congregado en dicha plaza. / El Ayuntamiento ha acordado hacer huésped de honor al señor Torrens durante su estancia en Cartagena» ${ }^{96}$. Se convirtió en un referente de la izquierda local: «... había sido teniente de la Guardia Civil y en el movimiento revolucionario de octubre de 1934 se pasó con su unidad al lado de los mineros asturianos, por lo que fue procesado y condenado... »97. Esa imagen se agigantó al ponerse al mando del batallón de milicias cartageneras - el aludido Fernando Condés- que, en los primeros días de la guerra, alistó la J.S.U.: «... luchó con entusiasmo y ayudó en el mismo proceso de la lucha a instruir militarmente a los que componíamos el batallón. Esta fue la primera unidad militar organizada que salió de Cartagena. Participamos en varios combates y tomamos varios pueblos, el último de ellos Colomera a unos kilómetros de la ciudad de Granada. Después, en todo el período de la guerra, la situación de este frente varió muy poco ${ }^{98}$. Aparecía retratado como un hombre de pocas palabras, que gozaba del respeto de sus subordinados: «... Torrens es el hermano miliciano. Torrens es un valiente, siendo el comandante jefe, es sólo un miliciano más, igual a todos. Cuida de nosotros más que de él mismo. Con decirle que Torrens jamás se ha puesto a comer sin que el último de los milicianos haya terminado, está todo dicho. Por eso lo queremos y con Torrens iríamos a donde nos dijese „99. Su situación no se regularizó hasta el 17 de octubre de 1936, cuando se dispuso su vuelta al servicio activo, siendo destinado a la Comandancia de Murcia $^{100}$.

\section{UNA INTERPRETACIÓN SESGADA}

El dictamen de la Comisión sobre ilegitimidad de poderes actuantes el 18 de julio de 1936 consideró la amnistía aprobada como una flagrante trasgresión en el ejercicio del poder. La de 1936 era la tercera de las otorgadas durante la etapa republicana. La de 1931 - ya mencionada—, se refirió a los delitos políticos, sociales y de imprenta, y se sustentaba en el «... deseo de contribuir al restablecimiento y afirmación de la paz pública...»101. Muy otro fue el sentido de la autorizada por Ley de 24 de abril de 1934, con las derechas en el poder, donde se incluían no sólo las ofensas al Jefe de Estado y a la forma de Gobierno y los delitos de rebelión y sedición militares, sino también otros de inequívoca elocuencia, como la evasión de capitales, las infracciones cometidas con motivo de la celebración de

96 La Tierra (Cartagena), 28 de julio de 1936.

97 AHPCE, Manuscritos, Tesis y Memorias. Carpeta 38. B. GARCÍA, Cartagena en el período de nuestra guerra, (s.a.).

98 Ibidem.

99 Cartagena Nueva, 22 de agosto de 1936.

100 Gaceta de Madrid, 19 de octubre de 1936, p. 408.

101 Gaceta de Madrid, 15 de abril de 1931, p. 195. 
elecciones y las originadas con la designación de jurados mixtos, al tiempo que quedaban sin efecto las expropiaciones sin indemnización de fincas rústicas ${ }^{102}$.

En la reconstrucción de los hechos acuñada desde los aparatos ideológicos del régimen franquista se falseó — de forma interesada — todo lo acontecido: «Las cárceles se vacían, sin esperar el decreto de amnistía» ${ }^{103}$. La mentira insufla toda la trama: «En la de Cartagena, los sublevados matan a un vigilante» ${ }^{104}$. Se altera radicalmente el contenido del indulto: «Y desde que la amnistía vació los penales, atracos y robos se repetían en Cartagena con frecuencia nunca conocida» ${ }^{105}$. Uno de los portavoces de la Falange murciana sitúa lo acontecido bajo el torcido epígrafe de Explosión de desórdenes, salvando la imagen de determinado cuerpo armado: «El día 17 de febrero se amotinaron los reclusos del penal de Cartagena, hiriendo de un disparo al empleado José Antonio García, hasta que por fin la Guardia Civil consigue dominarlos» ${ }^{106}$. La prensa local —bajo la situación política que siguió a la guerra - contribuyó a forjar ese perfil de caos y anarquía atribuidos al desgobierno republicano, desfigurando la verdad y glorificando, de paso, a los pacificadores: «... se encontraban en este penal los presos políticos, entre ellos los elementos principales de la Ezquerra Catalana, los asesinos de Dato y otros elementos de la F.A.I. / Este incendio fue provocado por reclusos políticos que ante la distinción que habían tenido los presos de la Ezquerra Catalana en dicha prisión, como acto de protesta incendiaron la nave [...] En aquellos días el ilustre general López-Pinto, Gobernador Militar de la Plaza, con energía y tesón fue uno de los primeros que entraron en dicho edificio reduciendo el motín» ${ }^{107}$.

No es difícil desentrañar la doblez. En la sentencia dictada por el asesinato de Eduardo Dato aparecen como autores Pedro Mateu Cusidó, Luis Nicolau Fort y Ramón Casanellas, declarado en rebeldía al haber huido a la Unión Soviética. Fueron condenados a la última pena. El 22 de enero de 1924, Alfonso XIII —con Primo de Rivera como dictador - le concedió el indulto, conmutando la sentencia de muerte por la inmediata de cadena perpetua ${ }^{108}$. El 21 de noviembre de 1924, Pedro Mateu - procedente del Penal de Figueras- ingresó en el de Cartagena. Aquí permaneció hasta el 14 de abril de 1931, al acogerse a la amnistía concedida con ocasión de la proclamación de la Segunda República. No estaba en 1936.

De la disposición de 1936 se aprovecharon los falangistas enjuiciados en los meses precedentes. Su glosa — desde aquella opción — diluye la gracia otorgada

102 Gaceta de Madrid, 25 de abril de 1934, pp. 548-549.

103 Cfr. ARRARÁS, J., Historia de la Segunda República Española, Madrid, Editora Nacional, 1968, t. IV, p. 68.

104 Vid. ARRARÁS, J., Historia de la cruzada española, Madrid, Ediciones Españolas, S.A., 1942, vol. II, p. 440.

105 Vid. ARRARÁS, Historia de la cruzada..., vol. VI, p. 26.

106 GARCÍA GALLUD, E., O esto o aquello, 14 de abril 1931 - 18 de julio 1936, Murcia, Imp. Guirao, 1971 , p. 174.

107 El Noticiero (Cartagena), 26 de enero de 1946.

108 Gaceta de Madrid, 23 de enero de 1924, p. 376. 
y recrimina al Gobierno: «Poco después del triunfo electoral del Frente Popular, se promulga la Ley de Amnistía prometida a sus huestes para amparar y beneficiar a los presos políticos socialistas y separatistas que habían intervenido directamente en la revolución de octubre de 1934, de los que una parte cumplían ya sentencia firme. A la amnistía decretada también pudieron acogerse los recientes detenidos, y falangistas de diversas poblaciones de la provincia fueron libertados, entre ellos algunos de Murcia, si bien por pocos días...» ${ }^{109}$. La persistencia en su actuación terrorista fue lo que los devolvió a la cárcel ${ }^{110}$.

Los presos comunes no obtuvieron ninguna ventaja. A comienzos de marzo algunos de ellos —un total de 34- fueron remitidos al Puerto de Santa María: «El motivo del traslado es el de carecer de alojamiento, debido a los desperfectos habidos en este Penal a causa del incendio que en el mismo promovieron los penados a raíz de las elecciones, y con objeto de proceder a la reparación de los daños para su mejor acondicionamiento '111. Una semana más tarde, el director sería desplazado al centro de San Miguel de los Reyes ${ }^{112}$.

No hubo suelta del presidio. Esa acción tuvo lugar el 16 de septiembre de 1936, en un contexto muy diferente, al ser pensada como una medida de reeducación revolucionaria: «A la terminación del juicio de ayer mañana, el Tribunal Popular, con los Jurados, se trasladó a la cárcel de San Antón, donde fueron puestos en libertad todos los presos que había por delitos comunes. / Antes de marcharse, el presidente del Tribunal, señor Sánchez Roca ${ }^{113}$, les hizo saber que los ponía en libertad para que fueran hombres honrados, que volvieran a una sociedad nueva y que el que no se encontrara con valor suficiente para vivir la nueva vida, que se quedara, porque el que reincidiera sería castigado con pena severísima, y aquellos que se dedicaran al robo y al pillaje pagarían con su vida. / Los presos dieron vivas a la República y algunos pidieron marchar al Frente» ${ }^{114}$.

La medida será refrendada con la amnistía decretada el 22 de enero de 1937 por Juan García Oliver como ministro de Justicia. Abarcaba —entre otras calificaciones- a los penados y encausados por delitos comunes cometidos con ante-

109 GARCÍA GALLUD, E., op. cit., p. 185.

110 AYALA, J.A., op. cit., pp. 92-93. GONZÁLEZ MARTÍNEZ, C., op. cit., p. 56.

111 Cartagena Nueva, 13 de marzo de 1936.

112 El Noticiero (Cartagena), 24 de marzo de 1936.

113 Se trata de Mariano Sánchez Roca, conocido periodista madrileño y prestigioso abogado que había defendido a los implicados en los sucesos de Asturias de 1934. Republicano federal y simpatizante de la CNT, conocerá una carrera meteórica. El 13 agosto de 1936 será nombrado auditor de la Escuadra; el 28 del mismo mes, juez de primera Instancia e Instrucción y el 11 de noviembre subsecretario del Ministerio Justicia, siendo su titular el anarquista Juan García Oliver. Se mantuvo en ese puesto hasta el 19 de mayo de 1937, coincidiendo con el cambio de Gobierno. Cfr. GARCÍA OLIVER, J., El eco de los pasos, Barcelona, Ruedo Ibérico, 1978, pp. 306-308. Sobre el Tribunal Popular de Cartagena vid. BERMEJO MERINO, C.; AYUSO HERRERA, M. y MARCOS RIVAS, J., «El Tribunal Popular de Cartagena», en Justicia en Guerra. Jornadas sobre la Administración de Justicia durante la guerra civil española: Instituciones y fuentes documentales, Madrid, Ministerio de Cultura, 1990, pp. 109-125. GONZÁLEZ MARTíNEZ, C., op. cit., pp. 240-243.

114 La Tierra (Cartagena), 17 de septiembre de 1936. 
rioridad al 15 de julio de 1936. Venía a legalizar una situación generalizada, amparándose - como hizo Sánchez Roca - en la realidad social que alumbraba en la España republicana: «Es un hecho evidente que una vez iniciado el movimiento de rebelión militar producto de la deslealtad de un grupo de generales traidores, el pueblo español, al aprestarse a la defensa de su libertad, no quiso prescindir del concurso de un gran número de ciudadanos que por efecto del medio social en que vivía España con anterioridad a la subversión, se hallaban cumpliendo condena o procesados por sus actividades contrarias a la legalidad establecida» ${ }^{115}$.

La derecha usó desde el principio un doble lenguaje, velando la conspiración que ya estaba en marcha contra la República: «Ya está todo: el señor Azaña en el Poder, los presos en la calle, los Ayuntamientos repuestos... Nada se ha escatimado para satisfacer a la masa triunfante en sus aspiraciones y ésta debe ser precisamente la razón fundamental de que los triunfantes se consideren satisfechos y no comprometan o arriesguen sus conquistas, permitiendo que la paz y la tranquilidad pública sean perfectas y que se acabe la lucha enconada de clases, sea perfecto el orden y se vean seguras las personas de todos los matices... ${ }^{116}$. La pasividad de la izquierda burguesa ante aquella trama abre un denso capítulo de interpretaciones, desde la confianza suicida a la complicidad ${ }^{117}$.

115 Gaceta de la República, 25 de enero de 1937, p. 500.

116 Cartagena Nueva, 14 de marzo de 1936.

117 Cfr. AVILÉS FARRÉ, J., op. cit., pp. 423-429. CRUZ, R., op. cit., pp. 218-223 y MUNIS, G., op. cit., pp. 250-266. 